Article

\title{
Rational design of stratified material with spatially separated catalytic sites as an efficient overall water-splitting photocatalyst
}

\author{
Yi-Lei Li, Xiao-Jing Wang, Ying-Juan Hao, Jun Zhao, Ying Liu, Hui-Ying Mu, Fa-Tang Li * \\ College of Science, Hebei University of Science and Technology, Shijiazhuang 050018, Hebei, China
}

\section{A R T I C L E I N F}

\section{Article history:}

Received 30 July 2020

Accepted 24 August 2020

Available online 22 November 2020

\section{Keywords:}

Stratified material

Hollow cubes

Overall water splitting

Anion/cation exchange

Spatially separated site

\begin{abstract}
A B S T R A C T
The development of metal sulfide catalysts with remarkable activity toward efficient overall photocatalytic water splitting remains challenging owing to the dominant charge recombination and deficient catalytic active sites. Moreover, in the process of water oxidation catalysis, the inhibition of severe photocorrosion is an immense task, requiring effective photogenic hole-transfer kinetics. Herein, stratified Co- $\mathrm{MnO}_{2} @ \mathrm{CdS} / \mathrm{CoS}$ hollow cubes with spatially separated catalytic sites were rationally designed and fabricated as highly efficient controllable catalysts for photocatalytic overall water splitting. The unique self-templated method, including a continuous anion/cation-exchange reaction, integrates a Co-doped oxidation co-catalyst $\left(\mathrm{Co}-\mathrm{MnO}_{2}\right)$ and a reduction co-catalyst $(\mathrm{CoS})$ on the nanocubes with uniform interface contact and ultrathin two-dimensional (2D) nanometer sheets. We demonstrate that the stratified $\mathrm{Co}-\mathrm{MnO}_{2} @ \mathrm{CdS} / \mathrm{CoS}$ hollow cubes can provide an abundance of active sites for surface redox reactions and contribute to the separation and migration of the photoionization charge carriers. In particular, CoS nanoparticles dispersed on the walls of CdS hollow cubes were identified as reduction co-catalysts accelerating hydrogen generation, while $\mathrm{Co}-\mathrm{MnO}_{2}$ nanosheets attached to the inner walls of the CdS hollow cube were oxidation co-catalysts, promoting oxygen evolution dynamics. Benefiting from the desirable structural and compositional advantages, optimized stratification of $\mathrm{Co}-\mathrm{MnO}_{2} @ \mathrm{CdS} / \mathrm{CoS}$ nanocubes provided a catalytic system devoid of precious metals, which exhibited a remarkable overall photocatalytic water-splitting rate $\left(735.4\left(\mathrm{H}_{2}\right)\right.$ and $\left.361.1\left(\mathrm{O}_{2}\right) \mu \mathrm{mol} \mathrm{h}^{-1} \mathrm{~g}^{-1}\right)$, being among the highest values reported thus far for CdS-based catalysts. Moreover, an apparent quantum efficiency (AQE) of $1.32 \%$ was achieved for hydrogen evolution at $420 \mathrm{~nm}$. This study emphasizes the importance of rational design on the structure and composition of photocatalysts for overall water splitting.
\end{abstract}

(C) 2021, Dalian Institute of Chemical Physics, Chinese Academy of Sciences. Published by Elsevier B.V. All rights reserved.

\section{Introduction}

Photocatalytic water splitting is a potential technique for the production of $\mathrm{H}_{2}$ in a sustainable manner, and thus has aroused considerable research interest as a promising energy conversion technology [1-7]. Although this process appears attractive, the majority of current developed photocatalytic wa- ter-splitting protocols require the addition of sacrificial agents (such as lactic acid and ethanol) due to several drawbacks: (1) insufficient catalytic active sites; (2) rapid photoelectron-hole pair recombination; (3) restricted formation of $\mathrm{O}_{2}$ due to the transfer of multiple electrons and protons in the photocatalyst to form the $0-0$ bond $(1.23 \mathrm{eV}$ ) [8-12]. For practical photolysis technology, one of the most challenging tasks in solar energy

\footnotetext{
* Corresponding author. Tel/Fax: +86-311-81668302; E-mail: lifatang@126.com

This work was supported by the National Natural Science Foundation of China (21776059), and the Natural Science Foundation for Distinguished Young Scholars of Hebei Province (B2015208010).

DOI: 10.1016/S1872-2067(20)63706-8 | http://www.sciencedirect.com/science/journal/18722067 | Chin. J. Catal., Vol. 42, No. 6, June 2021
} 
utilization is the development of a high-efficiency photocatalyst capable of directly decomposing pure water under visible-light irradiation $[13,14]$. Pivotal to achieving this goal is the rational design and synthesis of highly efficient water-splitting photocatalysts, capable of decomposing pure water into stoichiometric $\mathrm{H}_{2}$ and $\mathrm{O}_{2}$ without the need for sacrificial reagents [15].

Metal sulfides (e.g., CdS) are intriguing visible-light-active photocatalysts with a unique electronic structure, tunable optical properties, and appropriate band gaps and band edges [16-20]. However, the photocatalytic efficiency of CdS is poor owing to the high recombination rate of photogenerated electron-hole pairs. Morphology design is an effective strategy for generating high-efficiency catalysts [21-23]. Among the various possibilities, accurately designed hollow structures exhibit attractive properties for photocatalysis, including improved charge transfer and large specific surface areas [24-27]. In general, hollow materials can reduce the diffusion distance of photogenerated carriers and greatly improve the separation efficiency of photogenerated electron-hole pairs [28]. In addition, the support of co-catalysts on hollow materials is a recognized strategy for the improvement of photocatalytic activity. For example, Zhang et al. reported that hollow CdS-loaded CoS displayed enhanced photocatalytic hydrogen production activity [29]. The load of the reduced co-catalyst can effectively transfer the photogenerated electrons, and the holes remain in the valence band of the photocatalyst, thus increasing the lifetime of photogenerated electrons. However, the consumption of holes requires the addition of sacrificial agents. Without sacrificial addition, photogenic holes accumulated on CdS tend to oxidize crystal sulfide ions rather than participate in the generation of oxygen, leading to severe photocorrosion of CdS [30]. Therefore, in order to realize the overall photocatalytic water splitting by CdS and ensure the stability of cadmium sulfide, effective hole transfer is an important step. Recently, the effects of metal-oxide-assisted catalysts, such as $\mathrm{RuO}_{2}$ and $\mathrm{IrO}_{2}$, on water oxidation activity were studied using the metal oxides as hole traps [31]. However, high-cost noble metals are routinely used as hole collectors, considerably limiting their practical value. Recently, manganese oxide $\left(\mathrm{MnO}_{x}\right)$ has been used as an oxidation catalyst for the transfer of holes [32]. However, the reported $\mathrm{MnO}_{x}$ catalysts exhibited low activity in overall photocatalytic water splitting because of their poor conductivity and limited exposure to active sites. According to literature reports, the addition of cations, such as $\mathrm{Ni}, \mathrm{Co}$, or $\mathrm{Fe}$, into the manganese oxide matrix is an effective strategy for the improvement of its electrical conductivity and catalytic capacity [33]. However, this strategy has seldom been applied to manganese oxide to enhance its photocatalytic oxidation activity.

In addition, the achievement of efficient photocatalysis also depends on the delicate design and construction of catalysts with appropriate structures. Studies in recent years have shown that photocatalytic hydrogen production can be improved by depositing dual co-catalysts on the semiconductor surface, compared with the activity of corresponding single co-catalyst supports [34]. Due to the complexity of multicomponent assembly, previous studies have generally focused on the random synthesis of photocatalysts and co-catalysts, with- out the targeted design and control of nanostructures to optimize performance in terms of light absorption, charge separation, and surface redox reactions $[35,36]$. Thus, the principal challenge of photocatalyst synthesis is the accurate control of composite nanostructure formation from various compounds.

Ion exchange can introduce requisite ions into the parent material, effectively modifying the structure and composition of nanomaterials to create complex shell structures of various chemical compositions $[37,38]$. The assembly of oxide or sulfide hollow-structured catalysts via straightforward ion exchange has resulted in excellent electrocatalytic activities $[39,40]$. However, in the case of photocatalysts, nanomaterials need to possess multiple capabilities, such as sunlight absorption, charge separation and transfer, and surface reactivity, which complicate ion exchange requirements [41]. The Zhao group recently reported an elegant sequential strategy for the synthesis of core-shell structured photocatalysts with tunable chemical compositions and clean surfaces, which exhibited exceedingly high photocatalytic $\mathrm{H}_{2}$ production activity and stability [42]. Nevertheless because of the solid spherical structure and the use of a single co-catalyst, drawbacks remained, such as insufficient reactive sites and low photocarrier separation efficiency, which detrimental to its overall photocatalytic water-splitting performance. In order to obtain an efficient photocatalyst that meets the above requirements, it is necessary to control the morphology and composition of the material accurately, and to assemble several morphologies and compositions into the composite materials. Thus, the preparation of hollow catalysts with multicomponent and multi-morphology via the ion exchange synthetic method remains challenging.

Herein, while simultaneously considering composition design and morphology control, the synthesis of Co- $\mathrm{MnO}_{2} @ \mathrm{CdS} / \mathrm{CoS}$ hollow cubes supported by double co-catalysts was achieved via a sequential ion exchange reaction. The stratified Co- $\mathrm{MnO}_{2} @ \mathrm{CdS} / \mathrm{CoS}$ material ensures maximized contact and interface areas between the components, which is beneficial for the separation of photogenerated carriers. Furthermore, the two-dimensional (2D) nanosheet is encapsulated in a hollow structure by an ingenious ion etching reaction, which can further enlarge the specific surface area and provide abundant active sites. The principal preparation process entailed four reactions, as shown in Fig. 1. Preparation of graded hollow nanostructures using a ZIF-67 cube as the precursor to generate a ZIF-67@CoS heterostructure via a sulfidation reaction. Subsequently, the hierarchical Co- $\mathrm{MnO}_{2} @ \mathrm{CoS}$ heterostructure could be obtained by $\mathrm{Mn}^{2+}$ corrosion and subsequent thermal treatment. Co- $\mathrm{MnO}_{2}$, as 2D nanocrystals, is expected to increase the number of reactive sites. Then, the Co- $\mathrm{MnO}_{2} @ \mathrm{CoS}$ heterostructure cages prepared by the cation-exchange reaction were controllably transformed into the Co- $\mathrm{MnO}_{2} @ \mathrm{CdS} / \mathrm{CoS}$ hollow cages. The stratified morphology facilitates the separation and migration of charge, and the large specific surface area affords plentiful reaction sites facilitating photocatalytic water splitting. As expected, the Co- $\mathrm{MnO}_{2} @ \mathrm{CdS} / \mathrm{CoS}$ photocatalyst exhibited outstanding performance for overall photocatalytic water splitting, as well as 


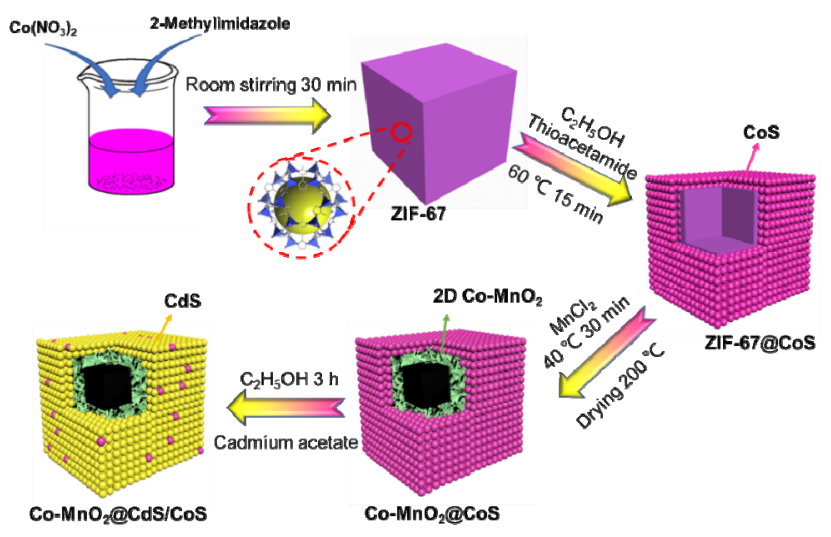

Fig. 1. Schematic illustration of hierarchical Co- $\mathrm{MnO}_{2} @ \mathrm{CdS} / \mathrm{CoS}$ hollow cube synthesis.

high stability.

\section{Experimental}

\subsection{Synthetic protocols}

Literature-guided synthesis of ZIF-67 nanocubes with several modifications [43]: $0.292 \mathrm{~g} \mathrm{Co}\left(\mathrm{NO}_{3}\right)_{2} \cdot 6 \mathrm{H}_{2} \mathrm{O}$ was added to $20 \mathrm{~mL}$ of deionized water containing cetyltrimethylammonium bromide (CTAB) (2 mg). Then, this solution was rapidly added to $70 \mathrm{~mL}$ of water containing $4.54 \mathrm{~g}$ of 2-methylimidazole and stirred vigorously for $30 \mathrm{~min}$ at $24^{\circ} \mathrm{C}$. Finally, the sediment was obtained through centrifugation and washed four times with $\mathrm{CH}_{3} \mathrm{OH}$.

Synthesis of hollow ZIF-67@CoS. $80 \mathrm{mg}$ of the obtained ZIF-67 mixture was placed into $40 \mathrm{~mL}$ of ethanol, containing $120 \mathrm{mg}$ of thioacetamide (TAA) and the mixture was stirred vigorously for $0.5 \mathrm{~h}$. Subsequently, the solution was poured into a distilling flask (100 $\mathrm{mL}$ in capacity), and kept in a preheated oven at $60{ }^{\circ} \mathrm{C}$ for $15 \mathrm{~min}$. Then, the resultant precipitate was washed with ethanol several times and dried at $60{ }^{\circ} \mathrm{C}$ overnight. The product was kept in a preheated oven at $60^{\circ} \mathrm{C}$ for 30 min to obtain the material labeled as hollow CoS.

Synthesis of hollow Co- $\mathrm{MnO}_{2} @ \mathrm{CoS}$ yolk-shell. $40 \mathrm{mg}$ of ZIF-67@CoS was added to $50 \mathrm{~mL}$ of ethanol solution containing $40 \mathrm{mg}$ of $\mathrm{MnCl}_{2} \cdot 4 \mathrm{H}_{2} \mathrm{O}$. Subsequently, the mixture was poured into a distilling flask (100 $\mathrm{mL}$ in capacity) and kept in a preheated oven at $40^{\circ} \mathrm{C}$ for $30 \mathrm{~min}$. Then, the obtained compounds were washed with ethanol several times and dried at $200{ }^{\circ} \mathrm{C}$ overnight.

Synthesis of hollow Co- $\mathrm{MnO}_{2} @ \mathrm{CdS} / \mathrm{CoS}$ cubes. Conversion of Co- $\mathrm{MnO}_{2} @ \mathrm{CoS}$ to $\mathrm{Co}-\mathrm{MnO}_{2} @ \mathrm{CdS} / \mathrm{CoS}$ hollow cubes was realized via an efficient cation-exchange method. Co- $\mathrm{MnO}_{2} @ \mathrm{CoS}$ hollow cubes $(30 \mathrm{mg}$ ) were placed into $20 \mathrm{~mL}$ of ethanol and $0.4 \mathrm{~g}$ of $\mathrm{Cd}\left(\mathrm{CH}_{3} \mathrm{COO}\right)_{2}$ was added to the above solution. The resultant mixture was stirred for $20 \mathrm{~min}$ and then placed in a $50 \mathrm{~mL}$ autoclave in an oven at $120^{\circ} \mathrm{C}$ for $1,2,3$, and $4 \mathrm{~h}$ under static conditions. The reaction products were obtained through centrifugation, washed four times with ethanol, and dried at 80 ${ }^{\circ} \mathrm{C}$ for $10 \mathrm{~h}$. The prepared products were designated as
Co- $\mathrm{MnO}_{2} @ \mathrm{CdS} / \mathrm{CoS}-1, \mathrm{Co}-\mathrm{MnO}_{2} @ \mathrm{CdS} / \mathrm{CoS}-2, \mathrm{Co}-\mathrm{MnO}_{2} @ \mathrm{CdS} /$ $\mathrm{CoS}-3$, and $\mathrm{Co}-\mathrm{MnO}_{2} @ \mathrm{CdS} / \mathrm{CoS}-4$, respectively.

Synthesis of hollow CdS/CoS and CdS cubes. Conversion of $\mathrm{CoS}$ to $\mathrm{CdS} / \mathrm{CoS}$ hollow cubes was realized via an efficient cation-exchange method. CoS hollow cubes (30 mg) were dispersed in $20 \mathrm{~mL}$ of ethanol and $0.4 \mathrm{~g} \mathrm{Cd}\left(\mathrm{CH}_{3} \mathrm{COO}\right)_{2}$ was added the above solution. The resultant mixture was stirred for 20 min and then placed in a $50 \mathrm{~mL}$ autoclave in an oven at $120^{\circ} \mathrm{C}$ for $3 \mathrm{~h}$. Following the reaction, the prepared products were collected, washed four times with ethanol, and dried under vacuum at $80{ }^{\circ} \mathrm{C}$ for $10 \mathrm{~h}$. The obtained products were designated as $\mathrm{CdS} / \mathrm{CoS}$. The resultant mixture was placed in an oven at $120^{\circ} \mathrm{C}$ for $8 \mathrm{~h}$ to generate the material labeled as hollow $\mathrm{CdS}$.

\subsection{Material characterization and analysis}

The crystal structures of the catalysts were determined by X-ray diffraction (XRD) with $\mathrm{Cu} K_{\alpha}$ radiation $(\lambda=1.5418 \AA)$. Catalyst morphology was analyzed via transmission electron microscopy (TEM) with a field emission gun operating at 200 $\mathrm{kV}$ (FEI Tecnai G2S-Twin), as well as by scanning electron microscopy (SEM) and high-resolution TEM (HRTEM). The Brunauer-Emmett-Teller (BET) specific surface area was determined via nitrogen sorption with an ASAP 2020 physisorption analyzer (U.S.A.) at 77 K. Elemental mapping was studied by TEM with an energy dispersive spectrometer. The photoluminescence (PL) emission spectra of the catalysts were obtained using a fluorescence spectrophotometer (Hitachi F-4600). The chemical nature of the as-prepared catalysts was studied using inductively coupled plasma mass spectrometry (ICPMS) (Perinlmer Optima 2000DV instrument). The time-resolved fluorescence decay spectra of the samples were also measured using an FS5 spectrometer (Edinburgh Instruments).

\subsection{Photoelectric testing}

Transient photocurrent responses and Mott-Schottky curves were measured on an electrochemical system on the CHI660E electrochemical workstation (Shanghai, China). Preparation of working electrode: $80 \mathrm{mg}$ of catalyst was placed in 1 $\mathrm{mL}$ DMF, and the suspension was applied to an FTO glass sheet to fabricate a $1.0 \mathrm{~cm} \times 1.5 \mathrm{~cm}$ electrode. The FTO glass sheets were then dried at $200{ }^{\circ} \mathrm{C}$. Light was produced by a $300 \mathrm{~W}$ Xe lamp simulator. $\mathrm{Na}_{2} \mathrm{SO}_{4}$ solution $(0.2 \mathrm{M})$ was used as the electrolyte.

\subsection{Photocatalytic hydrogen production}

Photocatalytic hydrogen production was conducted in a Pyrex reaction tank connected to a closed gas cycle and exhaust system. Each nanomaterial (10 mg) was placed in $100 \mathrm{~mL}$ of distilled water. The suspension was degassed for $30 \mathrm{~min}$ by $\mathrm{N}_{2}$ bubbling, and then it was irradiated with a xenon lamp $(\lambda \geqslant$ $420 \mathrm{~nm}$ ). During the photocatalytic process, the temperature was kept constant by circulating condensed water. The $\mathrm{H}_{2}$ and $\mathrm{O}_{2}$ contents generated from water splitting were analyzed by 
gas chromatography. Photocatalytic activity was evaluated by the average evolution rate of hydrogen and oxygen over $4 \mathrm{~h}$. After every $4 \mathrm{~h}$ of reaction, the suspension remained in the dark for $4 \mathrm{~h}$ prior to the next irradiation. This process was repeated in triplicates. The apparent quantum efficiency (AQE) was evaluated using a lamp equipped with a $420 \mathrm{~nm}$ band-pass filter. The AQE was calculated using Eq. (1).

$$
A Q E=\frac{\text { the number of evolved } \mathrm{H}_{2} \text { molecules } \times 2}{\text { the number of incident photons }} \times 100
$$

Moreover, to further illustrate the excellent photocatalytic activity of the catalyst, $10 \mathrm{mg} \mathrm{Co}-\mathrm{MnO}_{2} @ \mathrm{CdS} / \mathrm{CoS}$ was added to $50 \mathrm{~mL}$ of water with lactic acid $(3 \mathrm{~mL})$. The suspension was degassed for $30 \mathrm{~min}$ by $\mathrm{N}_{2}$ bubbling, and then it was irradiated with a xenon lamp $(\lambda \geqslant 420 \mathrm{~nm})$. During the photocatalytic process, the temperature was kept constant by circulating condensed water at $25^{\circ} \mathrm{C}$, and the hydrogen-producing activity was evaluated under these conditions. In addition, in order to study the effect of $\mathrm{CoS}$ and $\mathrm{Co}-\mathrm{MnO}_{2}$, the photocatalytic half-reaction was studied according to the above-described steps. On the one hand, the hydrogen-producing activities of $\mathrm{CdS}$ and CdS/CoS were studied by the addition of lactic acid (3 $\mathrm{mL}$ ) as a hole sacrificial agent. While on the other, the oxygen-producing activity of CdS and Co- $\mathrm{MnO}_{2} @ \mathrm{CdS}$ was examined by replacing the sacrificial agent with ferric sulfate $(4 \mathrm{mM})$ as an electron sacrificial agent.

\section{Results and discussion}

\subsection{Morphology and structural characterization}

Highly uniform ZIF-67 cubes were synthesized via a modified ligand-assisted approach employing $\mathrm{Co}^{2+}$ ions with 2-methylimidazole as an organic ligand [43]. XRD analysis indicated the successful synthesis of the ZIF-67 phase (Fig. S1) [44].ZIF-67 cube dimensions were obtained from the SEM images, the sides being approximately $250 \mathrm{~nm}$ in length (Figs. S2(a)-(c)). The magnifying SEM analysis of the ZIF-67 precursors revealed a highly uniform morphology exhibiting a slick surface (Fig. 2(a)). TEM confirmed that ZIF-67 presented as a solid cube (Fig. 2(e), Fig. S2(d)). These ZIF-67 cubes were converted into hierarchical ZIF-67@CoS yolk shells via TAA treatment at $60^{\circ} \mathrm{C}$ for $15 \mathrm{~min}$. After the reaction with TAA in ethanol for $15 \mathrm{~min}$, the XRD pattern demonstrated the continued presence of ZIF-67 cubes, but the diffraction peak intensities were somewhat reduced (Fig. S3). In addition, the diffraction peak for $\mathrm{CoS}$ was absent, suggesting that it exists in an amorphous form. The morphology retained the cubic form, while the surface became coarse (Fig. 2(b), Fig. S4(a), and (b)). Furthermore, the yolk-shell structure was revealed by TEM (Fig. 2(f) and Fig. S4(c)), wherein the shell was comprised of small nanoparticles, and the nuclei resembled ZIF-67. ZIF-67@CoS production was confirmed by elemental mapping analysis of the ZIF-67@CoS under TEM images (Fig. S5). As evident from Fig. S5, Co was distributed throughout the cube, although it was predominantly distributed in two regions. Combining the distribution of $\mathrm{N}$ and $\mathrm{S}$ elements, it can be seen that the external Co existed as

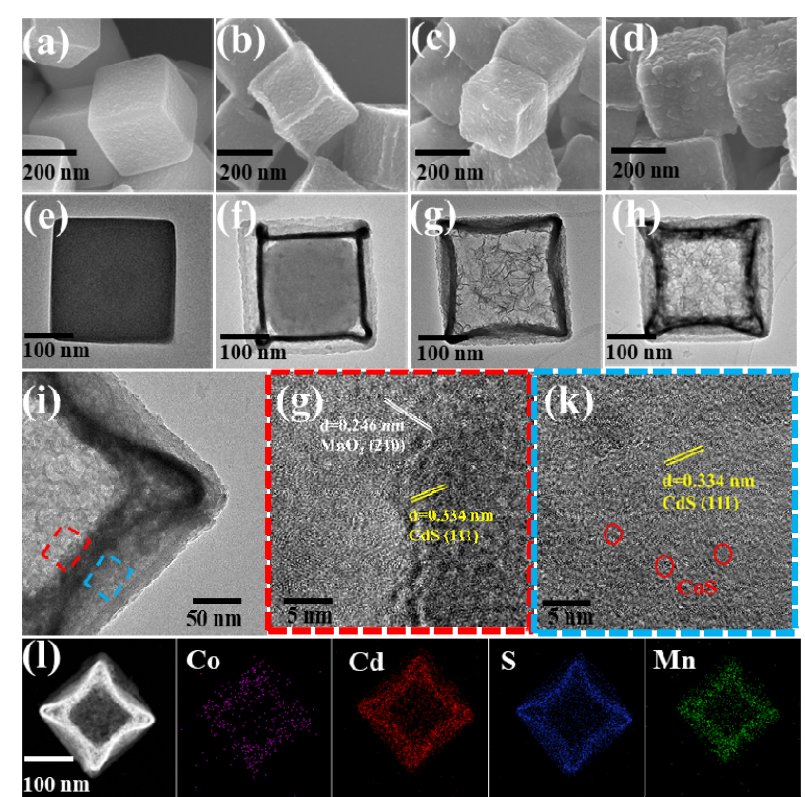

Fig. 2. SEM images of ZIF-67 (a), ZIF-67@CoS (b), Co-MnO2@CoS (c), and $\mathrm{Co}-\mathrm{MnO}_{2} @ \mathrm{CdS} / \mathrm{CoS}$ (d) samples; TEM images of ZIF-67 (e), ZIF-67@CoS (f), Co-MnO $\mathrm{MnCOS}_{2}$ (g), and Co- $\mathrm{MnO}_{2} @ \mathrm{CdS} / \mathrm{CoS}$ (h); (i) Amplified TEM of $\mathrm{Co}-\mathrm{MnO}_{2} @ \mathrm{CdS} / \mathrm{CoS}$; (j,k) HRTEM images of Co-MnO $2_{2} @ \mathrm{CdS} / \mathrm{CoS}$; (l) Scanning TEM (STEM) image of Co-MnO2@CdS/ $\mathrm{CoS}$ and its corresponding elemental mapping images.

$\mathrm{CoS}$, and the internal Co remained as ZIF-67. The contents of the two components can be adjusted by controlling the reaction time to obtain various shapes, and finally, hollow CoS can be generated. The time resolution experiment is presented in Fig. S6. In order to study the exact atomic ratio of cobalt sulfide, ICPMS analysis was performed, and the molar ratio of cobalt and sulfur atoms was 1:1.03, labeled as CoS.

Subsequently, the as-synthesized ZIF-67@CoS was reacted with $\mathrm{MnCl}_{2}$ in ethanol for $30 \mathrm{~min}$ at $40{ }^{\circ} \mathrm{C}$ and the product was dried at $200{ }^{\circ} \mathrm{C}$. After the reaction, the ZIF- 67 core was etched by $\mathrm{Mn}^{2+}$. The XRD pattern indicated the disappearance of ZIF-67 diffraction peaks, confirming that ZIF-67 had been etched in the reaction (Fig. S7). XRD measurements revealed characteristic peaks at $36.57^{\circ}$ and $42.50^{\circ}$, indexed to the (210) and (401) diffraction planes of $\mathrm{MnO}_{2}$ (JCPDS 42-1316), respectively [45]. FESEM images further illustrated that the morphology retained the cubic shape and the coarse surface (Fig. 2(c)). The damaged sample revealed that a hollow structure was formed inside the material (Fig. S8). The TEM images further illustrated that the interior of the hollow structure became a 2D nanosheet structure, indicating complete removal of the ZIF-67 cores (Fig. 2(g)). The Co- $\mathrm{MnO}_{2}$ in the interior existed as a 2D structure, increasing the number of active sites and enhancing photocatalytic activity. Furthermore, to explore the etching process of ZIF-67 by $\mathrm{Mn}^{2+}$, time-resolved experiments were performed. As shown in Fig. S9, the reaction products obtained at different time points revealed that the original cubic ZIF-67 was gradually etched into a 2D-layered material until all of the cubic ZIF-67 was completely etched. As further confirmed by elemental mapping analysis under TEM observation, a large 
number of Mn atoms were evenly distributed on the 2D nanocrystals, and a small amount of Co was present (Fig. S10). According to the above experiment, it can be concluded that the final product formed was Co-doped $\mathrm{MnO}_{2}$ (inside) and amorphous CoS (outside), marked as Co- $\mathrm{MnO}_{2} @ \mathrm{CoS}$. Coincidentally, according to literature reports, Co-doped manganese oxide has proven beneficial for generating oxygen in water splitting [46].

Finally, as-synthesized Co- $\mathrm{MnO}_{2} @ \mathrm{CoS}$ was transformed into the Co- $\mathrm{MnO}_{2} @ \mathrm{CdS} / \mathrm{CoS}$ stratified material via the cation-exchange reaction with $\mathrm{Cd}^{2+}$ ions at $120^{\circ} \mathrm{C}$. By adjusting the chemical reaction time, compounds of varying compositions can be synthesized. The samples were designated according to the reaction time employed for their synthesis; i.e., when the reaction was performed for $1 \mathrm{~h}$, the sample was designated as $\mathrm{Co}-\mathrm{MnO}_{2} @ \mathrm{CdS} / \mathrm{CoS}-1$, and so on. From the XRD results (Fig. S11), it is evident that the samples exhibited the characteristic diffraction peak of CdS following the exchange of cadmium ions, verifying the generation of CdS. As anticipated, ICPMS analysis revealed that with increasing reaction time from 1 to 4 $\mathrm{h}$, the $\mathrm{Cd}^{2+}$ atomic ratio gradually increased, and that of $\mathrm{Co}^{2+}$ accordingly decreased (Table S1). With prolonged reaction time, pure CdS could be obtained through hollow CoS, as shown in Fig. S12. SEM images demonstrated that the produced Co- $\mathrm{MnO}_{2} @ \mathrm{CdS} / \mathrm{CoS}$ materials preserved the overall cube shape perfectly after the cation-exchange reaction (Fig. 2(d)). As can be seen from the SEM images, there were no significant differences in the morphologies of $\mathrm{Co}-\mathrm{MnO}_{2} @ \mathrm{CdS} / \mathrm{CoS}-3$ and Co- $\mathrm{MnO}_{2} @ \mathrm{CoS}$ (Fig. 2(c) and (d)). TEM confirmed the composite nanostructure of the $\mathrm{Co}-\mathrm{MnO}_{2} @ \mathrm{CdS} / \mathrm{CoS}$ materials (Fig. 2(h)). The magnified side view of $\mathrm{Co}-\mathrm{MnO}_{2} @ \mathrm{CdS} / \mathrm{CoS}-3$ indicated that the outer nanoparticles were enlarged following the ion exchange reaction. Furthermore, the presence of $\mathrm{Co}-\mathrm{MnO}_{2}$ nanosheets was further observed by HRTEM by measuring lattice fringes (Figs. 2(i)-(k)). The lattice width of $0.334 \mathrm{~nm}$ corresponded to the (111) lattice of CdS. In addition, the lattice width of $0.246 \mathrm{~nm}$ corresponded to the (210) crystal face of $\mathrm{MnO}_{2}$. The crystal face of CdS was also found outside the cube [47]. No lattice fringe of $\operatorname{CoS}$ was observed, and thus we believe that $\mathrm{CoS}$ existed in an amorphous form, consistent with the XRD results of the precursor. The spatial distribution of various elements in $\mathrm{Co}-\mathrm{MnO}_{2} @ \mathrm{CdS} / \mathrm{CoS}$ was further examined under TEM observation by elemental mapping analysis. The experimental results indicated that $\mathrm{Mn}, \mathrm{Co}, \mathrm{Cd}$, and $\mathrm{S}$ were evenly distributed over the material (Fig. 2(I)). It is worth noting that the distribution range of $\mathrm{Mn}$ was smaller than that of other elements, suggesting that the inner layer was a manganese species, further verifying that $\mathrm{Co}-\mathrm{MnO}_{2} @ \mathrm{CoS}$ was a stratified material. As $\mathrm{Cd}^{2+}$ replaced $\mathrm{CoS}$, a large number of $\mathrm{CdS}$ particles were generated, leaving a small number of $\mathrm{CoS}$ scattered over the framework of CdS. The positioning of $\mathrm{Co}-\mathrm{MnO}_{2}$ on the interior, provided spatial separation between the electron co-catalyst $(\mathrm{CoS})$ and hole co-catalyst $\left(\mathrm{Co}-\mathrm{MnO}_{2}\right)$, which was beneficial for the efficient separation of photon-generated carriers. In order to study the elemental content, the molar ratios of Cd, Co, and Mn were analyzed by ICPMS, and the corresponding molar ratios are listed in Table S1. $\mathrm{N}_{2}$ adsorption-desorption tests revealed that the $\mathrm{Co}-\mathrm{MnO}_{2} @ \mathrm{CdS} / \mathrm{CoS}$ hollow cube exhibited a large BET specific surface area of 130.4 $\mathrm{m}^{2} \mathrm{~g}^{-1}$ (Fig. S13(a)). In addition, pore diameter analysis revealed that the pore diameter ranged from 3 to $6 \mathrm{~nm}$, and even up to $\sim 10 \mathrm{~nm}$, and the presence of these pores facilitated the flow of substrate $\left(\mathrm{H}_{2} \mathrm{O}\right)$ and product $\left(\mathrm{O}_{2}\right)$ in and out of the reaction sites, respectively (Fig. S13(b)) [48]. A hysteresis loop was performed on the $\mathrm{N}_{2}$ adsorption isotherm, suggesting the presence of mesopores on the wall of the hollow structure. A large specific surface area can increase the amount of catalytic sites, which is beneficial for the photolysis of water.

Moreover, an XPS experiment was conducted to determine the elemental composition of $\mathrm{Co}-\mathrm{MnO}_{2} @ \mathrm{CdS} / \mathrm{CoS}$. From the experimental results, it can be seen that the characteristic peaks of $\mathrm{Cd}, \mathrm{S}, \mathrm{Mn}, \mathrm{Co}$, and $\mathrm{O}$ existed, verifying the successful synthesis of the $\mathrm{Co}-\mathrm{MnO}_{2} @ \mathrm{CdS} / \mathrm{CoS}$ stratified material, using a double co-catalyst (Fig. 3). The XPS spectrum of the Co- $\mathrm{MnO}_{2} @ \mathrm{CdS} / \mathrm{CoS}$ sample is shown in Fig. 3(a). The two deconvoluted peaks in the $\mathrm{Cd} 3 d$ region at $411.8 \mathrm{eV}\left(\mathrm{Cd} 3 d_{3 / 2}\right)$ and $405.1 \mathrm{eV}\left(\mathrm{Cd} 3 d_{5 / 2}\right)$, together with the two peaks in the S $2 p$ region at $162.6 \mathrm{eV}\left(\mathrm{S} 2 p_{1 / 2}\right)$ and $161.5 \mathrm{eV}\left(\mathrm{S} 2 p_{3 / 2}\right)$ were identified as characteristic peaks of CdS (Figs. 3(b) and 3(c)). The XPS spectra of Co $2 p$ contained two deconvoluted peaks at 797.1 (Co $2 p_{1 / 2}$ ) and $781.1 \mathrm{eV}$ (Co $2 p_{3 / 2}$ ) (Fig. 3(d)). The Mn $2 p$ peaks located at 652.6 and $641.5 \mathrm{eV}$ corresponded to $\mathrm{Mn} 2 p_{1 / 2}$ and Mn 2p $3 / 2$, respectively (Fig. 3(e)). Moreover, compared with the reported XPS spectra of pure $\mathrm{MnO}_{2}$, the position of the Mn $2 p$ peak shifted slightly to a lower binding energy, caused by the doping of Co [46]. In addition, a high-resolution image of the 0 (1s) region was also analyzed. Fig. 3(f) shows that the major peak at $529.5 \mathrm{eV}$ was attributed to $\mathrm{Mn}-\mathrm{O}-\mathrm{Mn}$ bonds, while the other two peaks at 531.1 and $532.2 \mathrm{eV}$ arose from the 0 species of hydroxide ions and physically adsorbed water molecules, respectively [49]. This result clearly implied that $\mathrm{Co}-\mathrm{MnO}_{2} @ \mathrm{CdS} / \mathrm{CoS}$ with a double co-catalyst was successfully synthesized.

\subsection{Electron transfer mechanism}

To study the mechanism of the separation and transfer process of photogenic carriers, photoluminescence, time-resolved photoluminescence (TRPL) spectroscopy, and transient photocurrent response were studied. The fluorescence intensity of individual CdS was significantly higher than that of Co- $\mathrm{MnO}_{2} @ \mathrm{CdS} / \mathrm{CoS}$, indicating that the recombination rate of the photoinduced carrier in $\mathrm{Co}-\mathrm{MnO}_{2} @ \mathrm{CdS} / \mathrm{CoS}$ was greatly reduced (Fig. 4(a)). Such a decline was anticipated because the separation and transfer of photogenerated electron-hole pairs were facilitated, benefiting from $\mathrm{Co}-\mathrm{MnO}_{2}$ and $\mathrm{CoS}$ loading. In order to elucidate whether the decrease in fluorescence intensity was related to the decrease in $\mathrm{CdS}$ in the heterojunction, we conducted a comparative experiment, as shown in Fig. S14. The results suggest that a decrease in the quantity of CdS has a negligible effect on decreasing fluorescence intensity. The Co-MnO $\mathrm{Mn}_{2} @ \mathrm{CdS} / \mathrm{CoS}$ carrier was studied by TRPL spectroscopy (Fig. 4(b)). Photoelectron lifetimes can be obtained by TRPL spectroscopy. As seen in Table S2, the fitting result revealed that the carrier life span increased from 0.94 ns (CdS) to 2.98 

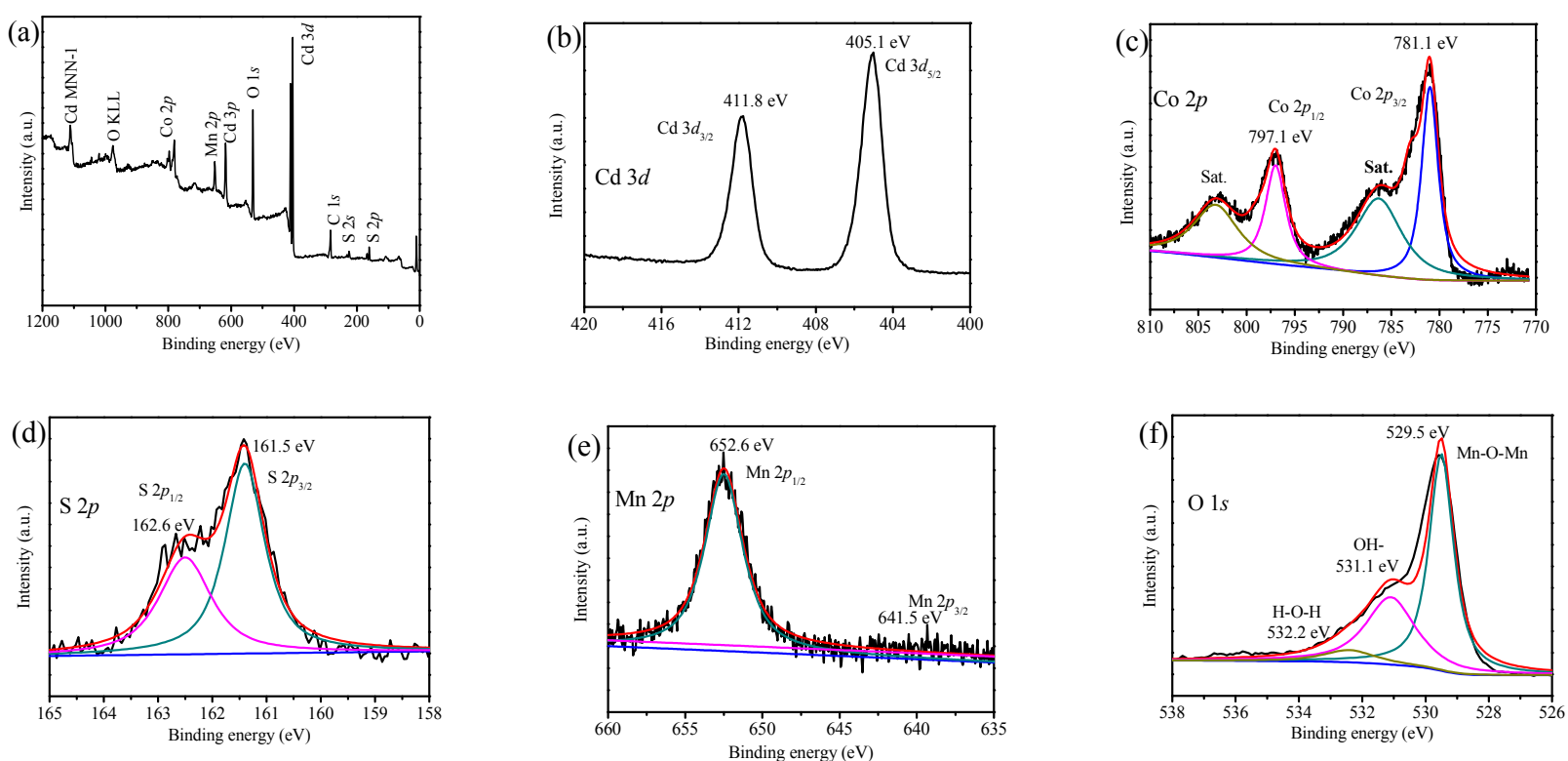

Fig. 3. XPS spectra of Co- $\mathrm{MnO}_{2} @ \mathrm{CdS} / \mathrm{CoS}$ heterostructures. (a) survey spectrum; high-resolution XPS spectra of Cd $3 d$ (b), Co $2 p$ (c), $2 p$ (d), Mn $2 p$ (e), and $01 s$ (f).
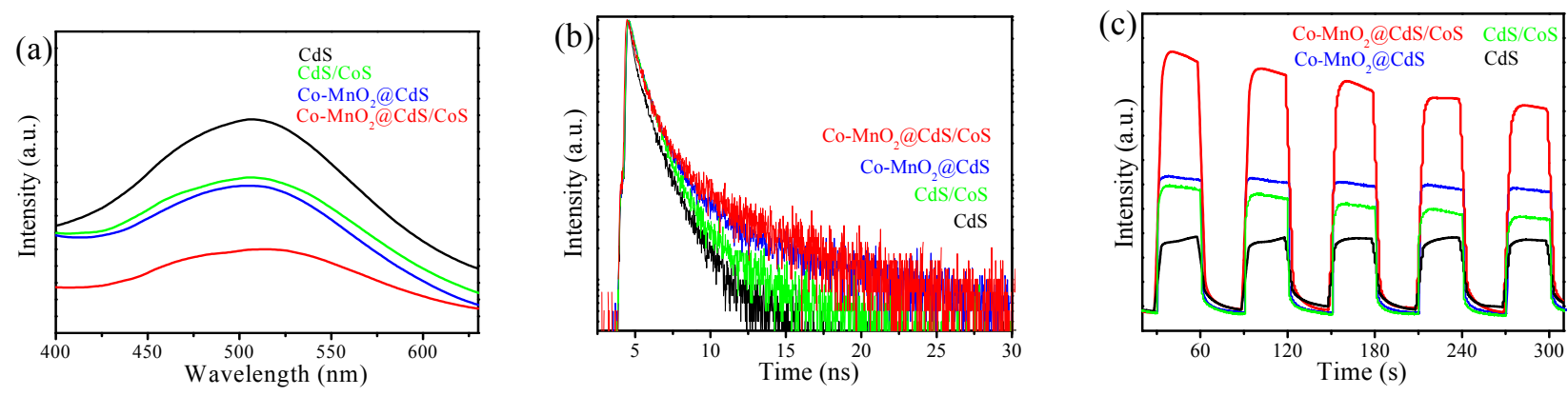

Fig. 4. Steady-state PL spectra (a), TRPL spectra (b), and transient photocurrent spectra (c) of CdS, CdS/CoS, $\mathrm{Co}_{-} \mathrm{MnO}_{2} @ \mathrm{CdS}$ and $\mathrm{Co}-\mathrm{MnO}{ }_{2} @ \mathrm{CdS} / \mathrm{CoS}$.

ns (Co- $\left.\mathrm{MnO}_{2} @ \mathrm{CdS} / \mathrm{CoS}\right)$. This increase in lifetime indicates that the photogenerated electron-hole pair transfer efficiency can be improved by $\mathrm{Co}-\mathrm{MnO}_{2}$ and $\mathrm{CoS}$ loading onto $\mathrm{CdS}$ by the tight connection [50]. On the other hand, the results of transient photocurrent experiments demonstrated that the photocurrent intensity of Co- $\mathrm{MnO}_{2} @ \mathrm{CdS} / \mathrm{CoS}$ was higher than that of CdS (Fig. 4(c)), validating that more effective separation and carrier transfer was occurring in $\mathrm{Co}-\mathrm{MnO}_{2} @ \mathrm{CdS} / \mathrm{CoS}$. The above results demonstrated that the separation efficiencies of photogenerated electron-hole pairs can be effectively enhanced by designing a stratified material with precise structure and composition. In addition, the materials comprising different components were analyzed with PL, TRPL, and photocurrent spectroscopy. Compared with the single co-catalyst material, the dual co-catalyst material had a lower fluorescence intensity, longer electron life, and higher photocurrent intensity, indicating that utilization of the dual co-catalyst can effectively improve the separation efficiency of photogenerated electron-hole pairs. At the same time, the addition of $\mathrm{Co}-\mathrm{MnO}_{2}$ can transfer the holes in the valence band of CdS, and further improve the separation efficiency of photogenic carriers.

\subsection{Photocatalytic performance}

The activity of each sample was evaluated by considering its overall photocatalytic water-splitting properties. The catalyst was tested in pure water under light irradiation $(\lambda \geqslant 420$ $\mathrm{nm}$ ). As shown in Fig. 5, the photocatalytic activity of the catalyst was tested after $4 \mathrm{~h}$ of the catalytic reaction. For pure CdS, trace amounts of hydrogen were detected $\left(10.2 \mu \mathrm{mol} \mathrm{g} \mathrm{g}^{-1} \mathrm{~h}^{-1}\right)$, but no oxygen was produced. As shown in Fig. 5(a), Co- $\mathrm{MnO}_{2} @ \mathrm{CdS} / \mathrm{CoS}-3$ exhibited remarkably high $\mathrm{H}_{2}$ (735.4 $\left.\mu \mathrm{mol} \mathrm{g}-1 \mathrm{~h}^{-1}\right)$ and $\mathrm{O}_{2}\left(361.1 \mu \mathrm{mol} \mathrm{g} \mathrm{g}^{-1} \mathrm{~h}^{-1}\right)$ production activity because of the introduction of $\mathrm{Co}-\mathrm{MnO}_{2}$ and $\mathrm{CoS}$, which further augmented the separation efficiency of carriers. The AQE of Co-MnO ${ }_{2} @ \mathrm{CdS} / \mathrm{CoS}-3$ at $420 \mathrm{~nm}$ attained 1.32\%. As shown in Fig. 5(b), the production rates of hydrogen and oxygen were well matched with the molar ratio of 2:1, and the overall catalytic activity was significantly improved. Indeed, the photocatalytic rate of $\mathrm{H}_{2}$ was approximately 72 -fold higher than that of CdS. In addition, the photocatalytic water-splitting activity of each Co- $\mathrm{MnO}_{2} @ \mathrm{CdS} / \mathrm{CoS}$ sample was also compared. Among 

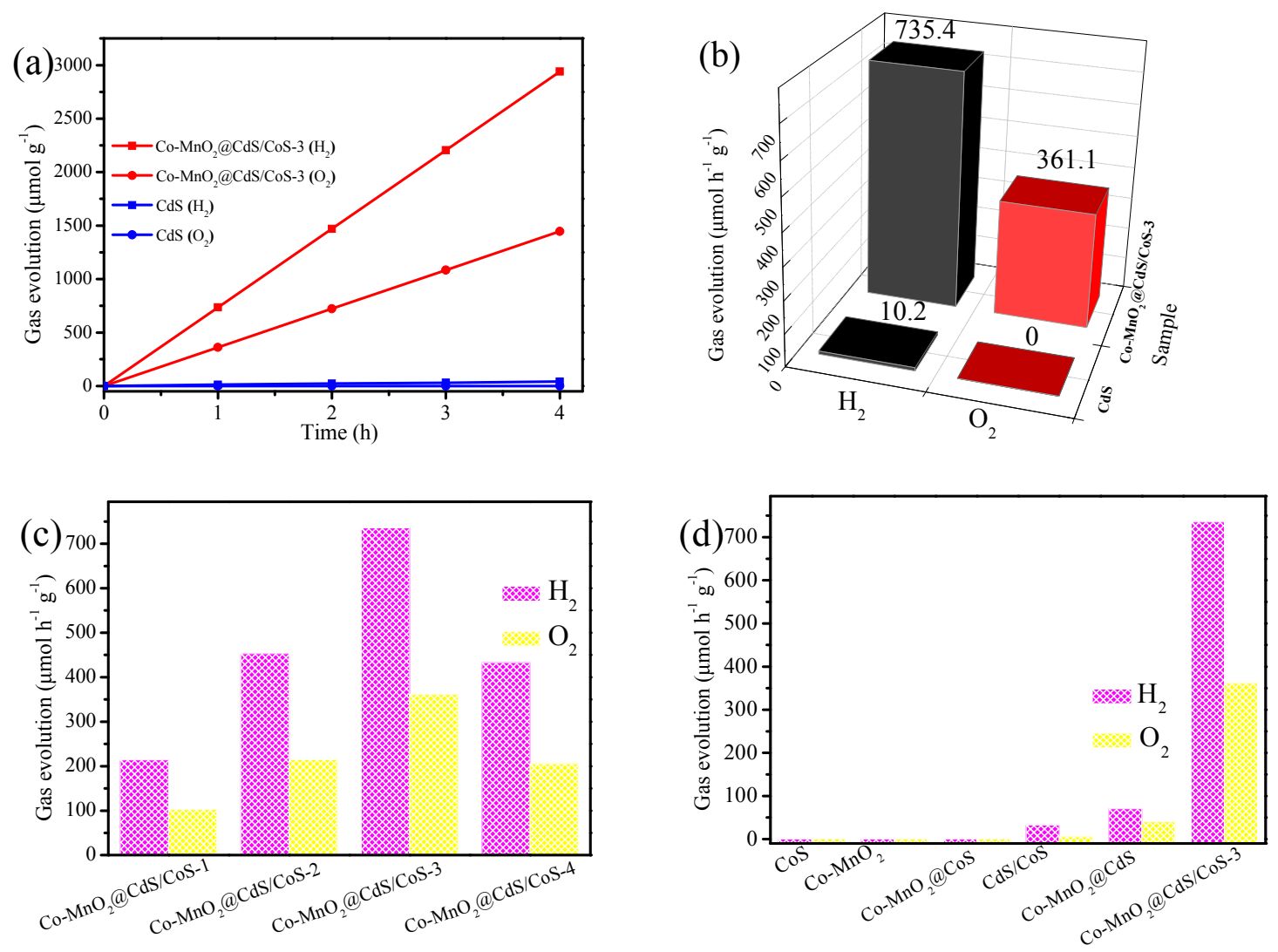

Fig. 5. (a) Time-yield plots of Co- $\mathrm{MnO}_{2} @ \mathrm{CdS} / \mathrm{CoS}-3$ and CdS; (b) Photocatalytic $\mathrm{H}_{2}$ and $\mathrm{O}_{2}$ evolution activities of CdS and Co-MnO $\mathrm{C}_{2} @ \mathrm{CdS} / \mathrm{CoS}-3$; (c) Photocatalytic $\mathrm{H}_{2}$ and $\mathrm{O}_{2}$ evolution activities of distinct response time samples; (d) Photocatalytic $\mathrm{H}_{2}$ and $\mathrm{O}_{2}$ evolution activities of various constituent samples.

them, Co-MnO $2 @ \mathrm{CdS} / \mathrm{CoS}-3$ exhibited the highest hydrogen production activity, indicating that the photocatalytic activity of the catalyst can be regulated by controlling the reaction time used to produce it (Fig. 5(c)). When the co-catalyst content was low, only a small portion of the electron holes generated by CdS can be effectively separated, and the photocatalytic efficiency is low. With an increase in co-catalyst content, the number of electron-hole pairs that can be effectively separated increases, and the photocatalytic activity increases. However, when the content of the co-catalyst is greater than the optimal amount, the photocatalytic activity decreases because excessive co-catalyst can cover the active site of the reaction and shield CdS from light irradiation. Moreover, an overabundance of co-catalyst provides recombination centers, recombining the resulting electron-hole pairs [51-53].

In order to further illustrate the high catalytic activity of Co- $\mathrm{MnO}_{2} @ \mathrm{CdS} / \mathrm{CoS}-3$, photocatalytic $\mathrm{H}_{2}$ experiments were conducted by the addition of lactic acid to the system (Fig. S15). The results indicated that $\mathrm{Co}-\mathrm{MnO}_{2} @ \mathrm{CdS} / \mathrm{CoS}-3$ displayed superb $\mathrm{H}_{2}$ production activity of $112.2 \mathrm{mmol} \mathrm{h}^{-1} \mathrm{~g}-1$. Furthermore, the photocatalytic water-splitting ability of Co- $\mathrm{MnO}_{2} @ \mathrm{CdS} / \mathrm{CoS}-3$ was superior to that of previously reported CdS-based photocatalysts (Table S3). The effects of various components on the catalytic properties were examined. As can be seen from Fig. 5(d), neither $\mathrm{CoS}, \mathrm{Co}-\mathrm{MnO}_{2}$, nor
Co- $\mathrm{MnO}_{2} @ \mathrm{CoS}$ exhibited photocatalytic properties, indicating that they existed as catalysts with an AQE of 0 . However, with the addition of Co- $\mathrm{MnO}_{2}$ to $\mathrm{CdS}$ the efficiency of oxygen production increased to a ratio of 1:1.75 to hydrogen with an AQE of $0.12 \%$, indicating that $\mathrm{Co}-\mathrm{MnO}_{2}$ played a critical role in overall photocatalytic water splitting. In other words, Co- $\mathrm{MnO}_{2}$ nanosheets attached to the inner wall of the CdS hollow cube act as oxidation co-catalysts, promoting oxygen evolution dynamics. In addition, in the absence of $\mathrm{Co}-\mathrm{MnO}_{2}$, the hydrogen production efficiency of $\mathrm{CdS} / \mathrm{CoS}$ did not increase significantly. To further illustrate the role of $\mathrm{CoS}$ and $\mathrm{Co}-\mathrm{MnO}_{2}$, the photocatalytic activity of the material was studied by adding lactic acid and ferric sulfate as sacrificial agents [54]. The results are shown in Fig. S16(a), wherein it is evident that compared with $\mathrm{CdS}$, the hydrogen production activity of $\mathrm{CdS} / \mathrm{CoS}$ was significantly higher, indicating that $\mathrm{CoS}$ was a suitable hydrogen production co-catalyst. On the other hand, as shown in Fig. S16(b), compared with CdS, the oxygen production of Co- $\mathrm{MnO}_{2} @ \mathrm{CdS}$ was markedly improved, indicating that $\mathrm{Co}-\mathrm{MnO}_{2}$ was an effective oxygen-producing co-catalyst. In order to highlight the advantages of the hollow structure, the material was subjected to ultrasonic treatment for $12 \mathrm{~h}$ to obtain the structure-collapse nanomaterials (damaged sample) (Fig. S17). According to the photocatalytic water-splitting test, the activity of the damaged material was only one third of that of the hollow structure (Fig. 

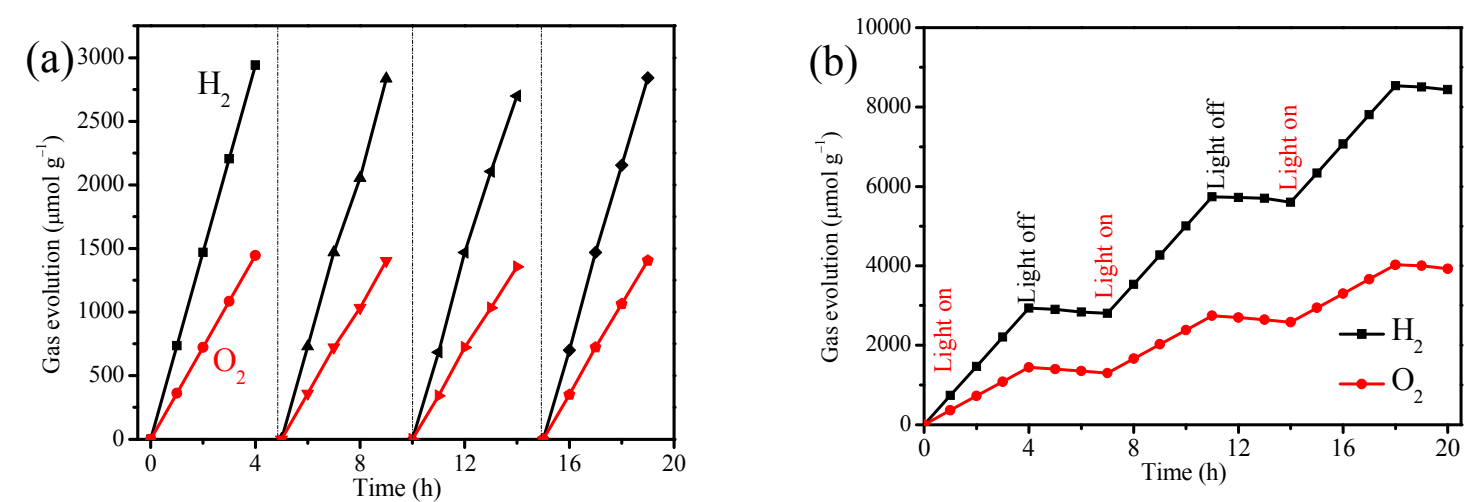

Fig. 6. (a) Cycling of photocatalytic water splitting over $\mathrm{Co}-\mathrm{MnO}_{2} @ \mathrm{CdS} / \mathrm{CoS}-3$; (b) Experimental study of the reverse reaction of Co-MnO ${ }_{2} @ \mathrm{CdS} / \mathrm{CoS}-3$.

S18).

For practical applications, in addition to favorable material properties, catalyst stability is likewise crucial. The stability of the optimized $\mathrm{Co}-\mathrm{MnO}_{2} @ \mathrm{CdS} / \mathrm{CoS}-3$ photocatalyst was evaluated by performing four consecutive reactions (Fig. 6(a)). The Co- $\mathrm{MnO}_{2} @ \mathrm{CdS} / \mathrm{CoS}-3$ sample displayed a stoichiometric ratio of hydrogen and oxygen gas evolution for $\mathrm{H}_{2} \mathrm{O}$ splitting. In the course of the four light reactions, the production of $\mathrm{H}_{2}$ and $\mathrm{O}_{2}$ continued to increase, while the amplitude increment did not decrease, indicating that the sample possessed good stability. This stable performance implied that the co-catalyst addition was beneficial to the inhibition of $\mathrm{CdS}$ photocorrosion. The stability of Co- $\mathrm{MnO}_{2} @ \mathrm{CdS} / \mathrm{CoS}-3$ was further verified by SEM and TEM analysis of the catalysts after the reaction (Fig. S19(a), (b)). XRD measurements were recorded for the sample after the reaction, and it was found that no obvious changes were observed in the crystalline structure compared with that of the original sample, indicating that the material was adequately stable in the reaction process (Fig. S19(c)). The XPS spectra of the $\mathrm{Co}-\mathrm{MnO}_{2} / \mathrm{CdS} / \mathrm{CoS}-3$ samples indicated that the chemical states of the sample did not change significantly during the photocatalytic process (Fig. S20). Overall, $\mathrm{Co}-\mathrm{MnO}_{2} / \mathrm{CdS} / \mathrm{CoS}-3$ exhibited high activity and stability for overall water splitting.

Another important factor affecting photocatalytic water splitting is the presence of severe adverse reactions of $\mathrm{O}_{2}$ and $\mathrm{H}_{2}$ on Pt co-catalysts to generate water [55]. Surprisingly, when the light was turned off, there was no significant reduction in the amount of hydrogen and oxygen produced (Fig. 6(b)), im-

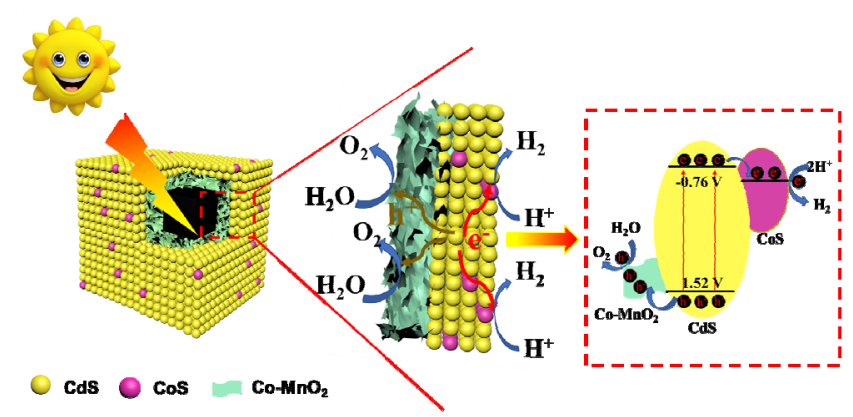

Fig. 7. Schematic illustration of the Co- $\mathrm{MnO}_{2} @ \mathrm{CdS} / \mathrm{CoS}$ hollow cube structures for overall photocatalytic water splitting. plying that no significant spontaneous backward reaction had occurred [56,57]. The sophisticated design of stratified materials resulted in an excellent photocatalytic hydrolysis performance.

The outstanding photocatalytic activity of the Co- $\mathrm{MnO}_{2} @ \mathrm{CdS} / \mathrm{CoS}$ hollow cubes was a result of the synergistic effects between structure and composition (Fig. 7). According to the UV-vis spectra, the band gap energy $\left(E_{\mathrm{g}}\right)$ of $\mathrm{CdS}$ was calculated to be $2.28 \mathrm{eV}$, as resolved from the Tauc plot (Fig. S21(a)) [58]. The Fermi energy level for CdS was $-0.76 \mathrm{~V}$ (vs. NHE), as determined from the Mott-Schottky (M-S) plots (Fig. $\mathrm{S} 21(\mathrm{~b})$ ) [59]. It is noteworthy that the $\mathrm{V}_{\mathrm{fb}}$ of $\mathrm{n}$-type semiconductors can generally approximate their conduction band potential $\left(E_{\mathrm{CB}}\right)$ [29]. Therefore, the valence band $\left(E_{\mathrm{VB}}\right)$ of CdS was calculated as $1.52 \mathrm{~V}$, and the corresponding structure diagram is shown in Fig. 7. The extrapolated $E_{\mathrm{CB}}$ of $\mathrm{CoS}$ was more positive than that of CdS (Fig. S21(b)), suggesting that the band structure possibly allows for charge transfer from CdS to CoS [60]. On the other hand, it has been proven that as $\mathrm{Co}-\mathrm{MnO}_{2}$ primarily acts as an oxidation catalyst $[61,62]$, it can transfer holes in the CdS valence band and promote the oxidation of water. Thus, two possible reasons exist for the outstanding photocatalytic activity of Co- $\mathrm{MnO}_{2} @ \mathrm{CdS} / \mathrm{CoS}$. First, the spatial separation of the two co-catalysts serves to orientate electrons and improve the separation efficiency of photogenerated electron-hole pairs. CoS nanoparticles act as reducing co-catalysts that facilitate photoinduced electron transfer to $\mathrm{CoS}$, thus enhancing the photocatalytic $\mathrm{H}_{2}$ evolution activity. Co- $\mathrm{MnO}_{2}$ nanosheets can also function as hole co-catalysts, promoting hole migration from CdS to $\mathrm{Co}-\mathrm{MnO}_{2}$, thus augmenting the photocatalytic oxygen evolution activity. Second, the reverse reaction of produced hydrogen and oxygen is severely inhibited. Overall, restricting the reverse reaction can substantially improve the photocatalytic effect.

\section{Conclusions}

In summary, a successful design for a water-splitting system was achieved with the sequential assembly of unique stratified Co- $\mathrm{MnO}_{2} @ \mathrm{CdS} / \mathrm{CoS}$ hollow cubes containing spatially separated dual co-catalysts as an efficient photocatalyst. After system- 
atic investigation, the design protocol was proven to be effective in enhancing the overall photocatalytic water-splitting performance $\left(\mathrm{CH}_{2}\right) 735.4$ and $\left.361.1\left(\mathrm{O}_{2}\right) \mu \mathrm{mol} \mathrm{h}^{-1} \mathrm{~g}^{-1}\right)$. An AQE of $1.32 \%$ at $420 \mathrm{~nm}$ was obtained. The $\mathrm{Co}-\mathrm{MnO}_{2} @ \mathrm{CdS} / \mathrm{CoS}$ hollow cubes with spatially separated dual co-catalysts enable the rapid transfer of photoinduced electrons and holes from $\mathrm{CdS}$ to the $\mathrm{CoS}$ and $\mathrm{Co}-\mathrm{MnO}_{2}$ catalytic sites, respectively, reducing the recombination rate of photoelectron-hole pairs. This study provides a novel approach for enhancing the overall photocatalytic water-splitting function of metal sulfides. Furthermore, this research provides a case study for demonstrating the general principles of materials chemistry, that is, that the microstructure of nanomaterials determines their properties.

\section{Electronic supporting information}

Supporting information is available in the online version of this article.

\section{References}

[1] R. Kuriki, T. Ichibha, K. Hongo, D. Lu, R. Maezono, H. Kageyama, O. Ishitani, K. Oka, K. Maeda, J. Am. Chem. Soc., 2018, 140, 6648-6655.

[2] Y. Xiao, G. Tian, W. Li, Y. Xie, B. Jiang, C. Tian, D. Zhao, H. Fu, J. Am. Chem. Soc., 2019, 141, 2508-2515.

[3] X. Tian, Y.-J. Sun, J.-Y. He, X.-J. Wang, J. Zhao, S.-Z. Qiao, F.-T. Li, J. Mater. Chem. A, 2019, 7, 7628-7635.

[4] J. Ran, J. Qu, H. Zhang, T. Wen, H. Wang, S. Chen, L. Song, X. Zhang, L. Jing, R. Zheng, S. Z. Qiao, Adv. Energy Mater., 2019, 9, 1803402.
[5] X. Chen, R. Shi, Q. Chen, Z. Zhang, W. Jiang, Y. Zhu, T. Zhang, Nano Energy, 2019, 59, 644-650.

[6] R. Gao, B. Cheng, J. Fan, J. Yu, W. Ho, Chin. J. Catal., 2021, 42, $15-24$.

[7] Y. Jia, D. Zhao, M. Li, H. Han, C. Li, Chin. J. Catal, 2018, 39, 421-430.

[8] M. F. Kuehnel, C. E. Creissen, C. D. Sahm, D. Wielend, A. Schlosser, K. L. Orchard, E. Reisner, Angew. Chem. Int. Ed., 2019, 58, 5059-5063.

[9] Z. Zhang, Z. Zhao, Y. Hou, H. Wang, X. Li, G. He, M. Zhang, Angew. Chem. Int. Ed., 2019, 58, 8862-8866.

[10] J. Ran, W. Guo, H. Wang, B. Zhu, J. Yu, S. Z. Qiao, Adv. Mater., 2018, 30, e1800128.

[11] Y.-L. Li, Y. Liu, Y.-J. Hao, X.-J. Wang, R.-H. Liu, F.-T. Li, Mater. Design, 2020, 187, 108379.

[12] H. Yang, J. Yin, R. Cao, P. Sun, S. Zhang, X. Xu, Sci. Bull., 2019, 64, 1510-1517.

[13] R. Li, Chin. J. Catal., 2017, 38, 5-12.

[14] Z. Li, L. Zhang, Y. Liu, C. Shao, Y. Gao, F. Fan, J. Wang, J. Li, J. Yan, R. Li, C. Li, Angew. Chem. Int. Ed., 2020, 59, 935-942.

[15] Y. Zhao, C. Ding, J. Zhu, W. Qin, X. Tao, F. Fan, R. Li, C. Li, Angew. Chem. Int. Ed., 2020, 59, 9653-9658.

[16] W. Wei, Q. Tian, H. Sun, P. Liu, Y. Zheng, M. Fan, J. Zhuang, Appl. Catal. B, 2020, 260, 118153.

[17] L. Su, L. Luo, H. Song, Z. Wu, W. Tu, Z.-J. Wang, J. Ye, Chem. Eng. J., 2020, 124346.

[18] Y. Li, T. Jin, G. Ma, Y. Li, L. Fan, X. Li, Dalton Trans., 2019, 48, 5649-5655.

[19] X. Zhang, H. Liang, H. Li, Y. Xia, X. Zhu, L. Peng, W. Zhang, L. Liu, T. Zhao, C. Wang, Angew. Chem. Int. Ed., 2019, 58, 3287-3293.

[20] R. Li, Chin. J. Catal., 2018, 39, 1180-1188.

[21] S. Wang, Y. Wang, S. Q. Zang, X. W. Lou, Small Methods, 2019, 4, 1900586.

[22] J. Qi, X. Lai, J. Wang, H. Tang, H. Ren, Y. Yang, Q. Jin, L. Zhang, R. Yu,

\section{Graphical Abstract}

Chin. J. Catal., 2021, 42: 1040-1050 doi: 10.1016/S1872-2067(20)63706-8

Rational design of stratified material with spatially separated catalytic sites as an efficient overall water-splitting photocatalyst

Yi-Lei Li, Xiao-Jing Wang, Ying-Juan Hao, Jun Zhao, Ying Liu, Hui-Ying Mu, Fa-Tang Li *

Hebei University of Science and Technology

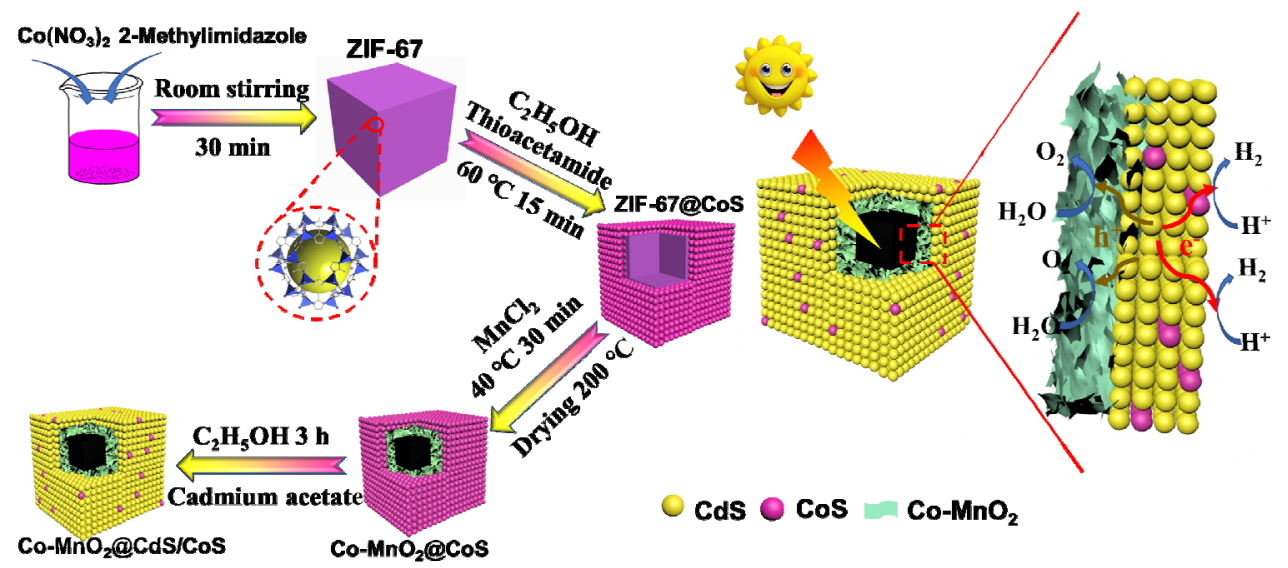

Stratified Co- $\mathrm{MnO}_{2} @ \mathrm{CdS} / \mathrm{CoS}$ hollow cubes enable rapid transfer of photoinduced electrons and holes from $\mathrm{CdS}$ to the $\mathrm{CoS}$ and $\mathrm{Co}-\mathrm{MnO}_{2}$ catalytic sites, respectively, thereby enhancing overall water-splitting performance. 
G. Ma, Z. Su, H. Zhao, D. Wang, Chem. Soc. Rev., 2015, 44, 6749-6773.

[23] X. Li, S. Guo, W. Li, X. Ren, J. Su, Q. Song, A. J. Sobrido, B. Wei, Nano Energy, 2019, 57, 388-397.

[24] D. Zheng, X.-N. Cao, X. Wang, Angew. Chem. Int. Ed., 2016, 55, 11512-11516.

[25] S. Wang, B. Y. Guan, X. W. D. Lou, J. Am. Chem. Soc., 2018, 140, 5037-5040.

[26] P. Zhang, S. Wang, B. Y. Guan, X. W. Lou, Energy Environ. Sci., 2019, $12,164-168$.

[27] J. Kong, Z. Rui, H. Ji, Ind. Eng. Chem. Res., 2017, 56, 9999-10008.

[28] P. Zhang, X. W. D. Lou, Adv. Mater., 2019, 31, e1900281.

[29] B. Qiu, Q. Zhu, M. Du, L. Fan, M. Xing, J. Zhang, Angew. Chem. Int. Ed., 2017, 56, 2684-2688.

[30] J. Chu, G. Sun, X. Han, X. Chen, J. Wang, W. Hu, I. Waluyo, A. Hunt, Y. Du, B. Song, P. Xu, Nanoscale, 2019, 11, 15633-15640.

[31] D. Wang, T. Hisatomi, T. Takata, C. Pan, M. Katayama, J. Kubota, K. Domen, Angew. Chem. Int. Ed., 2013, 52, 11252-11256.

[32] M. Xing, B. Qiu, M. Du, Q. Zhu, L. Wang, J. Zhang, Adv. Funct. Mater., 2017, 27, 1702624.

[33] Z. Ye, T. Li, G. Ma, Y. Dong, X. Zhou, Adv. Funct. Mater., 2017, 27, 1704083.

[34] J. Zhang, Z. Yu, Z. Gao, H. Ge, S. Zhao, C. Chen, S. Chen, X. Tong, M. Wang, Z. Zheng, Y. Qin, Angew. Chem. Int. Ed., 2017, 56, 816-820.

[35] B. Sun, W. Zhou, H. Li, L. Ren, P. Qiao, W. Li, H. Fu, Adv. Mater., 2018, 30, 1804282.

[36] J. Peng, J. Shen, X. Yu, H. Tang, Zulfiqar, Q. Liu, Chin. J. Catal., 2021, 42, 87-96.

[37] B. Li, Y. Zhang, D. Ma, Z. Xing, T. Ma, Z. Shi, X. Ji, S. Ma, Chem. Sci, 2016, 7, 2138-2144.

[38] D. Zhang, A. B. Wong, Y. Yu, S. Brittman, J. Sun, A. Fu, B. Beberwyck, A. P. Alivisatos, P. Yang, J. Am. Chem. Soc., 2014, 136, 17430-17433.

[39] Y. Zhou, W. Zhou, D. Hou, G. Li, J. Wan, C. Feng, Z. Tang, S. Chen, Small, 2016, 12, 2768-2774.

[40] C. Guan, X. Liu, W. Ren, X. Li, C. Cheng, J. Wang, Adv. Energy Mater., 2017, 7, 1602391.

[41] J. Chen, Z. Shen, S. Lv, K. Shen, R. Wu, X.-F. Jiang, T. Fan, J. Chen, Y. Li, J. Mater. Chem. A, 2018, 6, 19631-19642.

[42] X. Zhang, H. Liang, H. Li, Y. Xia, X. Zhu, L. Peng, W. Zhang, L. Liu, T. Zhao, C. Wang, Z. Zhao, C. T. Hung, M. M. Zagho, A. A. Elzatahry, W.
Li, D. Zhao, Angew. Chem. Int. Ed. Engl., 2020, 59, 3287-3293.

[43] H. Hu, B. Y. Guan, X. W. Lou, Chem, 2016, 1, 102-113.

[44] Y. Yun, H. Sheng, K. Bao, L. Xu, Y. Zhang, D. Astruc, M. Zhu, J. Am. Chem. Soc., 2020, 142, 4126-4130.

[45] Y. Zhang, M. Wu, Y. H. Kwok, Y. Wang, W. Zhao, X. Zhao, H. Huang, D. Y. C. Leung, Appl. Catal. B, 2019, 259, 118034.

[46] Y. Zhao, J. Zhang, W. Wu, X. Guo, P. Xiong, H. Liu, G. Wang, Nano Energy, 2018, 54, 129-137.

[47] S. Wang, B. Zhu, M. Liu, L. Zhang, J. Yu, M. Zhou, Appl. Catal. B, 2019, 243, 19-26.

[48] H. Xu, J. Cao, C. Shan, B. Wang, P. Xi, W. Liu, Y. Tang, Angew. Chem. Int. Ed., 2018, 57, 8654-8658.

[49] M. Wang, M. Shen, L. Zhang, J. Tian, X. Jin, Y. Zhou, J. Shi, Carbon, 2017, 120, 23-31.

[50] L. Shang, B. Tong, H. Yu, G. I. N. Waterhouse, C. Zhou, Y. Zhao, M. Tahir, L.-Z. Wu, C.-H. Tung, T. Zhang, Adv. Energy Mater., 2016, 6, 1501241.

[51] J. Wen, X. Li, H. Li, S. Ma, K. He, Y. Xu, Y. Fang, W. Liu, Q. Gao, Appl. Surf. Sci., 2015, 358, 204-212.

[52] J. Zhang, S. Z. Qiao, L. Qi, J. Yu, Phys. Chem. Chem. Phys., 2013, 15, 12088-12094.

[53] R.-B. Wei, Z.-L. Huang, G.-H. Gu, Z. Wang, L. Zeng, Y. Chen, Z.-Q. Liu, Appl. Catal. B, 2018, 231, 101-107.

[54] G. R. Bamwenda, T. Uesigi, Y. Abe, K. Sayama, H. Arakawa, Appl. Catal. A, 2001, 205, 117-128.

[55] T. Takata, C. Pan, M. Nakabayashi, N. Shibata, K. Domen, J. Am. Chem. Soc., 2015, 137, 9627-9634.

[56] Z. Pan, G. Zhang, X. Wang, Angew. Chem. Int. Ed., 2019, 58, 7102-7106.

[57] K. Maeda, K. Teramura, D. Lu, N. Saito, Y. Inoue, K. Domen, Angew. Chem. Int. Ed., 2006, 118, 7970-7973.

[58] S. Samanta, S. Martha, K. Parida, ChemCatChem, 2014, 6, 1453-1462.

[59] R. Li, J. Liu, X. Zhang, Y. Wang, Y. Wang, C. Zhang, X. Zhang, C. Fan, Chem. Eng. J., 2018, 339, 42-50.

[60] J. Fu, C. Bie, B. Cheng, C. Jiang, J. Yu, ACS Sustain. Chem. Eng., 2018, 6, 2767-2779.

[61] R. Li, F. Zhang, D. Wang, J. Yang, M. Li, J. Zhu, X. Zhou, H. Han, C. Li, Nat. Commun., 2013, 4, 1432.

[62] X. Zhou, Y. Fang, X. Cai, S. Zhang, S. Yang, H. Wang, X. Zhong, Y. Fang, ACS Appl. Mater. Interfaces, 2020, 12, 20579-20588.

\title{
合理设计具有空间分离催化位点的中空立方体顺序材料作为高效的 全解水光催化剂
}

\author{
李义否, 王晓静, 郝影娟, 赵 君, 刘 英, 穆惠英, 李发堂 \\ 河北科技大学理学院, 河北石家庄 050018
}

摘要: 通过精细的纳米结构和化学组成控制, 开发高效的全解水纳米光催化剂是一项具有挑战性的任务. 此外, 在光催化 水氧化的半反应过程中, 抑制纳米材料严重光腐蚀也是一项艰巨的任务, 需要有效地提高纳米材料光生空穴转移的动力 学. 为此, 本文通过可控的化学反应, 设计制备了具有空间催化活性位点分布的Co- $\mathrm{MnO}_{2} @ \mathrm{CdS} / \mathrm{CoS}$ 中空立方体顺序材料, 并用作可见光催化全解水催化剂. 采用MOFs作为自模板, 经过连续的阴离子交换和阳离子交换反应, 将Co掺杂的氧化助 催化剂(纳米片 $\mathrm{Co}-\mathrm{MnO}_{2}$ ) 和还原助催化剂(纳米粒子 $\mathrm{CoS}$ )同时整合到中空的立方体 $\mathrm{CdS}$ 纳米材料中, 使得超薄的二维纳米片 $\mathrm{Co}-\mathrm{MnO}_{2}$ 与立方体的内部界面均匀接触, 能够有效地提高空穴的转移效率. 同时, $\mathrm{CoS}$ 纳米粒子均匀分散在CdS纳米材料的 壁上, 能够有效地转移光生电子, 从而提高光生电子-空穴对的分离效率. 实验测试表明, $\mathrm{Co}-\mathrm{MnO}_{2} @ \mathrm{CdS} / \mathrm{CoS}$ 中空立方体顺 序材料可以为表面氧化-还原反应提供丰富的反应活性位点, 同时有助于提高 CdS 纳米材料光生电子-空穴对的分离和迁移 效率. 特别是分散在 $\mathrm{CdS}$ 中空立方体壁面上的 $\mathrm{CoS}$ 纳米颗粒被确定为加速氢气生成的还原型助催化剂, 能够促进水中氢离 
子生成氢气; 而附着在 $\mathrm{CdS}$ 中空立方体内壁上的 $\mathrm{Co}-\mathrm{MnO}_{2}$ 纳米片被确定为促进氧演化动力学的氧化型助催化剂, 能够促进 水生成氧气. 因此, 在本实验中, 得益于理想的纳米结构和化学组成方面的优势, $\mathrm{Co}-\mathrm{MnO}_{2} @ \mathrm{CdS} / \mathrm{CoS}$ 纳米立方体显示了高 效的光催化全解水性能: 在没有贵金属作为助催化剂存在时, 它显示了很好的整体光催化水分解效率 $\left(735.4\left(\mathrm{H}_{2}\right)\right.$ 和361.1 $\left.\left(\mathrm{O}_{2}\right) \mu \mathrm{mol} \mathrm{h}^{-1} \mathrm{~g}^{-1}\right)$, 超过了大多数文献报道的 $\mathrm{CdS}$ 基催化剂光解水效率. 此外, 以 $420 \mathrm{~nm}$ 单波长光为入射光, 进行了量子效率 $(\mathrm{AQE})$ 测试, 最优的 $\mathrm{Co}-\mathrm{MnO}_{2} @ \mathrm{CdS} / \mathrm{CoS}$ 纳米材料的表观 $\mathrm{AQE}$ 达 $1.32 \%$. 本文合成的顺序材料为构筑具有活性位点空间分布 的高效全解水催化剂提供了新的思路.

关键词: 顺序材料; 空心立方体; 整体水裂解; 阴离子/阳离子交换; 空间分离位点

收稿日期: 2020-07-30. 接受日期: 2020-08-24. 上网日期: 2020-11-22.

*通讯联系人. 电话/传真: (0311)81668302; 电子信箱: lifatang@126.com

基金来源：国家自然科学基金(21776059); 河北省杰出青年自然科学基金(B2015208010).

本文的电子版全文由Elsevier出版社在ScienceDirect上出版(http://www.sciencedirect.com/science/journal/18722067). 